\title{
COURTISER SARDY
}

Michèle Vinet

Traverser ton auréole-chaleur, vaporeuse de rosée-matin. Écouter dans l'air le frisson de ton passé, entendre son murmure, ses échos et sa voix de vent. Deviner tes racines, étudier les âpres troncs des cultures disparues. M'enivrer des parfums-encens de ton maquis, ses dédales, son lacis.

Soudain, un mulet grince une ode barbelée au jour. Un concert de clochettes de vaches s'ébroue dans tes cheveux-sommeil convoquant le jaune fiancé du firmament. Grise fanfare de tes oliveraies, tes chauds vignobles sur mes sens. Aube framboisée. Supplice et volupté.

Land Rover, intrépide et cahoteux, désinvolte au bord des précipices, aspirant aux sommets escarpés. Une Vierge-poussière fleurie dans sa nichecime. En contre bas, lits blancs de rivières desséchées, passages de bêtes, de pastoureaux. Le soupir des plaines au soleil, la langueur des clôtures de figues de Barbarie.

Armée de cyprès, soldats fiers et valeureux, caressant le grand Nulle Part tout bleu. Le souffle sucré de l'eucalyptus, oraison sur l'arrogance de tes rochers, le sel marin derrière tes yeux. Les doigts crochus de tes grottes, pierres-prières millénaires, stalagmites du cœur de la planète. Son pouls, son eurythmie.

Dans mon sang, de rouge, de grenat, la complainte des bergers, le bêlement des moutons. Paisibles troupeaux batifolant dans les champs. Sabots sourds sur le sol. Douce Sardaigne, ton terroir-velours, l'odeur des langoustiers, la nacre des mâts de beaupré, ton climat-soie sur la peau.

Venus et repartis les peuples d'antan. Vestiges de l'homme-déjà sous l'indifférence de l'homme de l'heure. Carcasses et momies dans ta passion contemporaine. Sur ton eau turquoise, vogue, chaude île et blanc voilier. Chante, Sardy la belle, pour t'entendre vibrer dans l'Univers. Sur tes prés, danse pieds nus, marque le siècle de tes saltarelles enjouées. 
Là-bas, grognent les guerres. Les hommes s'entretuent. Chez toi, coquillage, le temps s'ouvre et se referme sur tes perles-idylles, soustrait le pèlerin à son siècle aliéné. Dans le mystère de tes origines, la mistelle de ton raisin, une promesse loin de l'échiquier mondial, ses affaires et ses misères, ses solitudes néons, sa pauvreté, ses homicides.

Vive ta fraîcheur de lauriers et d'hibiscus. Tes mers et tes côtes Paradiso et Serena, ton corail et tes temples. Tes navires et traversiers. Tes cafés, ta participation tabacchi et giornali à la modernité.

Sur ma table alors, ton vin de pays. Parlons des temps qui courent en dégustant tes olives et ton fromage au miel. Intime festin, loin des bandits d'honneurs et des liaisons futiles. Ton accordéon, ton hymne national pour le dégager de ses toiles d'araignée. Sèche la fierté de tes larmes, et dignes, partons main dans la main. Sur mes lèvres, une ivresse inusitée.

À nos épousailles, anneaux de cordage et de varech. Plateaux de liège et ripaille de porcelet rôti et fruits de mer grillés. Princier repas où l'amour est convié. Nos sommeils dans tes villages perchés, sur le sable de tes rives. Nous bénirons les jours et les lunes à deux. Des pierres de notre faim du monde, bâtissons de nouveaux nuraghes. Victoires et défaites oubliées.

Au diable Rome ou l'Internet, Sardy. Je t'aimerai jusqu'à l'envers du temps. 